\title{
Gambaran Pengetahuan Bidan dan Perawat Tentang VKDB di Puskesmas Prabumulih Sumatera Selatan
}

\author{
Sri Utami ${ }^{1}$, Muhamad Yunus ${ }^{2}$, Deviani Utami ${ }^{3}$
}

Fakultas Kedokteran Universitas Malahayati Bandar Lampung, sriiuthami0@gm23ail.com Departemen Bedah Fakultas kedokteran Universitas Malahayati Bandar Lampung, yunusevanadam@gmail.com

Departemen Kesehatan Masyarakat Fakultas Kedokteran Universitas Malahayati Bandar Lampung, devi_joan@yahoo.com

\begin{abstract}
ABSTRAK
Perdarahan intrakranial merupakan perdarahan yang berbahaya pada bayi. Dampak perdarahan intrakranial berupa kematian dan gejala sisa, seperti hidrosefalus, atrofi serebral, ensefalopati, dan epilepsi yang akan mengganggu tumbuh kembang. Salah satu penyebab perdarahan intrakranial adalah Perdarahan karena Kekurangan Vitamin $K$ atau Vitamin $K$ Deficiency Bleeding (VKDB). Adapun perdarahan intrakranial karena kekurangan vitamin $K$ dapat dicegah dengan cara dengan pemberian vitamin Kl pada bayi baru lahir. Tujuan: Mengetahui gambaran tingkat pengetahuan tenaga kesehatan tentang perdarahan intrakranial spontan yang disebabkan karena vitamin $K$ deficiency bleeding di Puskesmas Prabumulih Sumatera Selatan Tahun 2020 Prabumulih Sumatera Selatan Tahun 2020. Jenis penelitian yang digunakan dalam penelitian ini adalah deskriptif dengan desain cross sectional. Sampel yang digunakan pada penelitian ini adalah perawat dan bidan yang bekerja di Puskesmas Prbumulih Sumatra Selatan yang telah memenuhi syarat kriteria pada penelitian ini. Pada penelitian ini didapatkan frekuansi tingkat pengetahuan cukup responden sebanyak 31 orang dengan presentase 46,3\%. Kesimpulan penelitian ini, bidan di puskesmas Prabumulih Sumatra Selatan memiliki tingkat pengetahuan yang cukup tentang perdarahan intrakranial akibat kekurangan vitamin K Perawat di puskesmas Prabumulih Sumatra Selatan memiliki tingkat pengetahuan yang cukup tentang perdarahan intrakranial akibat kekurangan vitamin K. Penelitian ini diharapakan bisa memberi informasi kepada masyarakat tentang pengetahuan perdarahan intrakranial karena kekurangan vitamin $K$, sehingga angka kejadian perdarahan intrakranial karena kekurangan vitamin $K$ dan kematian bayi dapat berkurang
\end{abstract}

Kata Kunci : perdarahan intrakranial, pengetahuan, defisiensi vitamin $k$

\begin{abstract}
Intracranial hemorrhage is a dangerous bleeding in infants. The impact of intracranial bleeding is in the form of death and sequelae, such as hydrocephalus, cerebral atrophy, encephalopathy, and epilepsy which will interfere with growth and development. One of the causes of intracranial bleeding is bleeding due to Vitamin K deficiency (VKDB). Meanwhile, intracranial bleeding due to vitamin $K$ deficiency can be prevented by giving vitamin Kl to newborns. This study aimed to know the description of the level of knowledge of health workers about spontaneous intracranial bleeding caused by vitamin K deficiency bleeding at the Prabumulih Health Center, South Sumatra in 2020. The type of research used in this research is descriptive with a cross sectional design. The samples used in this study were nurses and midwives who worked at the Prabumulih Health Center in South Sumatra who had met the criteria in this study. The result showed that the frequency of sufficient knowledge of respondents was found as many as 31 people with a percentage of 46.3\%. In conclusion Midwives at the Prabumulih health center in South Sumatra have a sufficient level of knowledge about intracranial bleeding due to vitamin $K$ deficiency. It is hoped that this study can provide information to the public about the knowledge of intracranial bleeding due to vitamin $K$ deficiency, so that the incidence of intracranial bleeding due to vitamin $K$ deficiency and infant mortality can be reduced.
\end{abstract}

Keywords: intracranial bleeding, knowledge, vitamin $k$ deficiency

Korespondensi Author : Sri Utami, Universitas Malahayati, email: sriiuthami0@gmail.com, nomer telpon: 085273184996 


\section{PENDAhuluan}

Perdarahan intrakranial merupakan perdarahan yang berbahaya pada bayi. Dampak perdarahan intrakranial berupa kematian dan gejala sisa, seperti hidrosefalus, atrofi serebral, ensefalopati, dan epilepsi yang akan mengganggu tumbuh kembang. Salah satu penyebab perdarahan intrakranial adalah VKDB. ${ }^{1}$

Pada tahun 1894 Towsend adalah orang pertama yang memperkenalkan istilah ini. Perdarahan intrakranial akibat kekurangan vitamin $\mathrm{K}$ ini diperkenalkan sebagai perdarahan yang bersumber dari berbagai tempat pada bayi sehat tanpa trauma. Kemudian pada tahun 1929 dan menyatakan hubungan perdarahan kranial spontan dengan kekurangan vitamin $\mathrm{K}$, kemudian pada tahun 1937 Brinkhous dkk mengemukakan hubungan antara kekurangan vitamin $\mathrm{K}$ dengan $\mathrm{HDN} .^{2}$

Perdarahan akibat kekurangan vitamin $\mathrm{K}$ dapat juga disebut Hemorogic Disease of the New Born (HDN) adalah kelainan yang disebabkan oleh penurunan aktivitas faktor koagulasi yang tergantung pada vitamin $\mathrm{K}$ (faktor II, VII, IX, dan X) sedangkan faktorfaktor selain vitamin $\mathrm{K}$ seperti kadar fibrinogen, trombosit, masih dalam batas normal. Perdarahan intrakranial merupakan perdarahan yang berbahaya pada bayi. Dampak perdarahan intrakranial berupa kematian dan gejala sisa, seperti hidrosefalus, atrofi serebral, ensefalopati, dan epilepsi yang akan mengganggu tumbuh kembang. Salah satu penyebab perdarahan intrakranial adalah Perdarahan karena Kekurangan Vitamin $\mathrm{K}$ (VKDB). ${ }^{3}$ Angka kejadian VKDB bervariasi antara 0,25-1,5\% pada tahun 2016, dan menurun menjadi 00,44\% pada 10 tahun terakhir dengan adanya program pemberian profilaksis vitamin $\mathrm{K}$ di Amerika Serikat. ${ }^{4}$ Belum ada studi populasi dari negara berkembang namun terdapat beberapa laporan kasus dari wilayah asia tenggara terutama. UNICEF memperkirakan berdasarkan suhu tropis insidens di negara berkembang bervariasi dari 28 hingga 72 per 100000 kelahiran. $^{5}$

Perdarahan intrakranial merupakan masalah klinis penting karena berkaitan dengan tingginya prevalensi, yang kadang disertai dengan gejala neurologis yang serius hingga banyak menyebabkan kematian. ${ }^{3}$ Pada tahun 2004 penelitian perdarahan intrakranial dilakukan oleh Danielsson et al di Hanoi pada penelitian ini didapatkan 233 bayi yang mengalami perdarahan intrakranial. Dengan tingkat mortalitas sebesar Sembilan persen, dan $46 \%$ diantaranya mengalami masalah neurologis termasuk kejang, hemiparesis, dan hidrosefalus. ${ }^{6}$ Penelitian lain yang dilakukan oleh D'Souza dan Subba Rao pada tahun 2003 didapatkan 14 bayi mengalami perdarahan intrakranial pada onset lambat VKDB, dengan angka mortalitas sebesar $57 \%$ dan gejala neurologis sebesar $36 \%{ }^{1}$

Penyakit APCD merupakan salah satu penyakit gangguan koagulasi yang paling sering dijumpai pada masa bayi kurang dari satu tahun.Dari ketiga klasifikasi APCD berdasarkan awitannya, tipe lambat yang paling sering muncul dengan manifestasi perdarahan intrakranial. APCD tipe lambat mengalami puncak kejadian padasekitar bulan ke dua, namun beberapa laporan kasus menyebutkan dapat terjadi hingga umur satu tahun, Insiden APCD tipe lambat di asia adalah sekitar 25-80 /100000 kelahiran yang lebih tinggi dibandingkan di negara maju yaitu sekitar 425/100000 kelahiran hidup. ${ }^{7}$

Acquired Prothrombin Complex Deficiency (APCD) merupakan suatu gangguan hemostasis akibat kekurangan dari kompleks protrombin yang tidak terbentuk akibat disfungsi faktor-faktor pembekuan yang dependen terhadap vitamin K. Istilah sindrom Acquired Prothrombin Complex Deficiency (APCD) pada bayi pertama kali diperkenalkan oleh Bhanchet pada tahun $1966 .{ }^{8}$ Sebelumnya disebut sebagai Hemorrhagic disease of the newborn namun 
istilah ini mulai banyak ditinggalkan karena manifestasi perdarahan dapat terjadi di luar periode neonatus. Istilah yang mulai banyak diadopsi dalam berbagai publikasi adalah vitamin $\mathrm{K}$ deficiency bleeding sesuai dengan patofisiologinya. ${ }^{8}$

Perdarahan intrakranial pada VKDB merupakan penyakit yang dapat dicegah dengan pemberian profilaksis vitamin $\mathrm{K}$ saat lahir. Pemberian profilaksis ini sudah terstandar sejak adanya rekomendasi oleh American Academy of Pediatrics pada tahun 1961 yaitu semua bayi baru lahir harus diberikan profilaksis vitamin $\mathrm{K}$ secara parenteral dengan dosis $0,5-1 \mathrm{mg}$ atau oral dengan dosis $1-2 \mathrm{mg}^{5}$

Di Indonesia dengan angka kematian bayi sekitar 41 per 1000 kelahiran kita belum memiliki data nasional tentang APCD. Di Thailand angka kesakitan akibat APCD adalah 1:1200 (Mc Ninch, 2010). Angka kejadian RSCM. Faktor risiko untuk APD antara lain tidak adanya profilaksis vitamin $\mathrm{K}$ saat lahir, ASI eksklusif, diare kronik dan penggunaan antibiotik berkepanjangan. ${ }^{9}$ Penelitian berbasis rumah sakit berikut dilakukan untuk mengetahui profil klinis, faktor risiko dan luaran pasien dengan perdarahan intrakranial terkait APCD.

Oleh karena itu dibutuhkan suatu kebijakan nasional penambahan vitamin K pada bayi guna menunjang program pemberian ASI eksklusif di Indonesia dalam rangka menurunkan angka kesakitan dan kematian bayi baru lahir. Kejadian pendarahan karena kekurangan vitamin $\mathrm{K}$ pada bayi baru lahir dilahirkan cukup tinggi berkisar 0,25-0,5\%. Untuk mencegah terjadinya pendarahan tersebut, semua bayi baru lahir normal dan cukup bulan perlu diberi vitamin $\mathrm{K} 1$ peroral $1 \mathrm{mg} /$ hari selama 3 hari, sedangkan bayi resiko tinggi diberi vitamin $\mathrm{K} 1$ parenteral dengan dosis 0,5-1 mg IM. Di Indonesia selama ini pemberian vitamin K1 umumnya hanya diberikan pada bayi baru lahir yang memiliki risiko saja seperti BBLR, bayi lahir dengan tindakan traumatis, bayi lahir dari ibu yang mengkonsumsi obat anti koagulan, obat anti kejang. Berkaitan dengan kasus KIPI (kejadian ikutan pasca imunisasi) yang diduga karena kekurangan vitamin $\mathrm{K}$, dimana petugas kesehatan di lapangan tidak mengetahui bahwa berbagai kasus KIPI sebenarnya dapat dicegah dengan pemberian profilaksis vitamin $\mathrm{K} 1$, maka perlu suatu pedoman teknik tentang pemberian profilaksis vitamin $\mathrm{K} 1.5$

Salah satu faktor yang penting untuk menurunkan angka kematian bayi adalah penyediaan pelayanan kesehatan yang berkualitas yang mempunyai keterampilan dan pengetahuan dalam pencegahan timbulnya permasalahan dan mengatasinya lebih dini, dan penyediaan pelayanan maternal dan neonatal yang berkualitas, setiap persalinan ditolong oleh bidan yang terlatih. ${ }^{4}$

Pencegahan yang dilakukan salah satunya dengan memberikan vitamin K1 pada bayi baru lahir yang dilakukan oleh tenaga kesehatan. Vitamin K1 dapat mencegah terjadinya risiko perdarahan, dimana efek yang paling berbahaya terjadinya perdarahan intrakranial. Dengan pemberian vitamin $\mathrm{K} 1$ dapat mengurangi angka kematian perinatal. ${ }^{4}$ Di Indonesia banyak yang mengalami pendarahan pasca persalinan pada bayi baru lahir. Hal ini disebabkan karena sedikitnya kadar vitamin $\mathrm{K}$ dalam tubuh bayi baru lahir. Sedangkan salah satu fungsi vitamin $\mathrm{K}$ adalah sebagai faktor pembeku darah.

\section{METODOLOGI}

Jenis penelitian ini mengunakan metode penelitian deskriptif dengan menggunakan desain penelitian crosssectional. Penelitian ini dilaksanakan di puskesmas Prabumulih Sumatera Selatan. Pada penelitian ini peneliti menggunakan teknik sampling total purposive sampling dimana dalam penelitian ini peneliti mengambil seluruh tenaga kesehatan sebanyak 67 sampel di Puskesmas Prabumulih Sumatera Selatan yang memenuhi kriteria inklusi dan eksklusi penelitian ini . 


\section{HASIL DAN PEMBAHASAN}

Pada penelitian ini didapatkan data frekuensi berdasarkan kelompok usia, jenis kelamin dan pekerjaan yang menjadi responden pada penelitian di Puskesmas Prabumulih Sumatera Selatan. Data yang diperoleh berdasarkan kuisioner terhadap 67 orang responden sebagai berikut :

Tabel 1. Tingkat pengetahuan

Berdasarkan Usia, Jenis Kelamin dan

\begin{tabular}{lcc}
\multicolumn{3}{c}{ Profesi } \\
\hline \multicolumn{1}{c}{$\mathrm{N}$} & $\%$ \\
\hline Kelompok usia & & \\
$20-30$ tahun & 9 & $13,4 \%$ \\
$31-40$ tahun & 36 & $53,7 \%$ \\
Diatas 40 tahun & 22 & $32,8 \%$ \\
\hline Total & $\mathbf{6 7}$ & $\mathbf{1 0 0 \%}$ \\
\hline Jenis kelamin & & \\
Laki - laki & 18 & $26,9 \%$ \\
Perempuan & 49 & $73,1 \%$ \\
\hline Total & $\mathbf{6 7}$ & $\mathbf{1 0 0 \%}$ \\
\hline Jenis Pekerjaan & & \\
Perawat & 41 & $61,2 \%$ \\
Bidan & 26 & $38,8 \%$ \\
\hline Total & $\mathbf{6 7}$ & $\mathbf{1 0 0 \%}$ \\
\hline
\end{tabular}

Berdasarkan tabel 1, bahwa frekuensi berdasarkan kelompok usia bidan dan perawat yang menjadi responden di Puskesmas Prabumulih Sumatera Selatan, paling banyak pada balita diatas 31-40 tahun dengan jumlah 36 orang dengan presentase $54,7 \%$. , paling banyak ialah responden dengan jenis kelamin perempuan sebanyak 49 orang dengan presentase $73,1 \%$.

Pada penelitian ini didapatkan data frekuensi berdasarkan tingkat pengetahuan bidan dan perawat di Puskesmas Prabumulih Sumatera Selatan yang menjadi responden. Data yang diperoleh berdasarkan kuisioner terhadap 67 orang responden sebagai berikut :
Tabel 2. Tingkat Pengetahuan Bidan

\begin{tabular}{cllll} 
& \multicolumn{3}{c}{ dan Perawat } & \\
\hline Tingkat & \multicolumn{2}{c}{ Jenis Pekerjaan } & & \\
\cline { 2 - 4 } Pengetahuan & Perawat & Bidan & & Persentase \\
\hline Kurang & 10 & 5 & 15 & $22,4 \%$ \\
\hline Cukup & 18 & 13 & 31 & $46,3 \%$ \\
\hline Baik & 13 & 8 & 21 & $31,3 \%$ \\
\hline Total & 41 & 26 & 67 & $100 \%$ \\
\hline
\end{tabular}

Berdasarkan tabel 2 diatas menunjukan bahwa frekuensi berdasarkan tingkat pengetahuan responden di Puskesmas Prabumulih Sumatera Selatan, diketahui sebanyak 10 perawat dan 5 bidan yang memiliki tingkat pengetahuan kurang dengan presentases sebesar $22,4 \%$. Pada tingkat pengetahuan cukup perawat sebanyak 18 dan bidan 13 dengan presentase tingkat pengetahuan sedang sebesar 46,3\%. Pada tingkat pengetahuan baik ditemukan sebanyak 13 responden perawat dan 8 responden bidan dengan presentase sebesar $31,3 \%$.

Pada penelitian ini peneliti mengambil beberapa aspek untuk menilai tingkat pengetahuan bidan dan perawat yang menjadi responden penelitian ini, adapun aspek yang diambil pada penelitian ini adalah: mengetahui, mengerti, dan mengaplikasi. Pada aspek mengetahui peneliti menyertakan 11 pertanyaan tentang perdarahan intrakranial karena kekurangan vitamin K. Pada aspek mengerti peneliti menyertakan 14 pertanyaan tentang perdarahan intrakranial karena kekurangan vitamin K. Pada aspek pengaplikasian peneliti menyertakan 5 pertanyaan.

Adapun pertanyaan pada aspek mengetahui perdarahan intrakranial karena kekurangan vitamin $\mathrm{K}$ paling banyak dijawab benar oleh bidan dan perawat di Puskesmas Prabumulih Sumatera Selatan adalah perdarahan intrakranial akibat kekurangan vitamin $\mathrm{K}$ sangat berbahaya bagi neonatus 62 responden menjawab benar hanya 5 responden menjawab salah. Pertanyaan kedua paling banyak dijawab benar adalah perdarahn intrakranial akibat 
kekurangan vitamin $\mathrm{K}$ dapat dicegah sebanyak 62 responden menjawab benar dan hanya 5 responden menjawab salah.

Pada Aspek mengerti terdapat 14 pertanyaan yang ditanyakan kepada responden yang paling banyak dijawab benar oleh bidan dan perawat di Puskesmas Prabumulih Sumatera Selatan adalah vitamin $\mathrm{K}$ membantu pembekuan darah 62 responden menjawab benar hanya 5 responden menjawab salah. Pertanyaan kedua paling banyak dijawab benar adalah pemeriksaan bleeding time untuk penegakkan diagnose PDVK sebanyak 59 responden menjawab benar dan hanya 8 responden menjawab salah.

Pertanyaan yang paling banyak dijawab salah oleh bidan dan perawat adalah massa protrombin tidak perlu dievaluasi dalam penegakkan PDVK 55 responden menjawab salah dan hanya 12 responden yang menjawab benar. Pertanyaan kedua paling banyak dijawab salah adalah peningkatan tekanan intrakranial merupakan salah satu gejala PDVK sebanyak 42 responden menjawab salah dan hanya 25 responden menjawab benar.

Pada Aspek Aplikasi terdapat 5 pertanyaan yang ditanyakan kepada responden, pertanyaan yang paling banyak dijawab benar oleh bidan dan perawat di Puskesmas Prabumulih Sumatera Selatan adalah vitamin K1 merupakan Provilaksi PDVK 57 responden menjawab benar hanya 10 responden menjawab salah.

Pengetahuan (knowledge) merupakan hasil tahu setelah orang melakukan penginderaan terhadap suatu objek tertentu atau sesuatu yang diketahui berkaitan dengan proses pembelajaran. Penginderaan terjadi melalui panca indera manusia, yaitu indera penglihatan, indera pendengaran, indera penciuman, indera perasa, dan indera peraba. Sebagian besar pengetahuan diperoleh dari mata dan telinga. ${ }^{10}$

Faktor yang mempengaruhi tingkat pengetahuan sesorang antara lain adalah pendidikan, penggalaman. ${ }^{11}$ Sementara epidemiologi dari perdarahan intracranial karena kekurangan vitamin $\mathrm{K}$ di asia sebanyak 2580/10.000 kelahiran sementara itu di Indonesia masih belum memiliki data tentang perdarahan intrakranial akibat kekurangan vitamin $\mathrm{K} .{ }^{7} \mathrm{Hal}$ ini menyebabkan banyak ketidaktauan perawat dan bidan tentang perdarahan intrakranial karena kekurangan vitamin $\mathrm{K}$. Hal ini dikarenakan perawat dan bidan di Puskesmas Prabumulih tidak mendapatkan banyak pengalaman tentang percdarahan intrakranial karena kekurangan vitamin $\mathrm{K}$.

Secara keseluruhan tingkat pengetahuan bidan dan perawat dikategorikan cukup, hal ini dapat dilihat terdapat pertanyaan yang dijawab salah oleh responden. Hal ini dapat dikarenakan responden kurang mempelajari salah satu penyebab angka kematian bayi (AKB) adalah perdarahan intracranial akibat kekurangan vitamin K. Puskesmas prabumulih bukan menjadi tempat rujukan pada kasus perdarahan intracranial karena kekurangan vitamin $\mathrm{K}$, oleh sebab itu banyak bidan dan perawat masih belum mengetahui tentang perdarahan intrakranial. Hal ini membuat kekhawatiran apabila terjadi kasus PDVK pada bayi baru baru lahir di wilayah kerja Puskesmas Prabumilih Sumatra Selatan, dikarenakan kekurangan pengalaman dan pengetahuan yang dikategorikan cukup membuat salah satu program pemerintah untuk menurutkan angka kematian bayi (AKB) tidak dapat berjalan lancar. Untuk itu diperlukan pembekalan teori tentang angka kematian bayi AKB pada perwat dan bidan, khususnya pada kasus pdvk.

Kasus PDVK ini merupakan kasus yang sering terlewatkan di Puskesmas maupun dokter umum lainnya, hal ini dikarenakan kekurangan alat untuk mendiagnosa PDVK seperti CT scan. Namun PDVK ini dapat didiagnosa melalui anamnesis dan gejala umum yaitu berupa penonkolan yang keras pada ubun-ubun bayi, pucat, dan penurunan kesadaran pada bayi.

Penelitian sebelumnya dilakukan oleh Debora pada tahun 2015 tentang pengeahuan bidan tentang pemberian vitamin $\mathrm{K}$ dan sikap dalam mencegah defisiensi vitamin $K$ 
didapatkan pengetahuan bidan mayoritas pengetahuan bidan adalah pengetahuan cukup dimana 11 responden dapat dikategorikan tingkat pengetahuan cukup.

\section{KESIMPULAN DAN SARAN KESIMPULAN}

Bidan di Puskesmas Prabumulih Sumatera Selatan memiliki tingkat pengetahuan yang cukup tentang perdarahan intrakranial akibat kekurangan vitamin K. Perawat di Puskesmas Prabumulih Sumatra Selatan memilikitingkat pengetahuan yang cukup tentang perdarahan intrakranial akibat kekurangan vitamin $\mathrm{K}$

\section{SARAN}

Bagi Tempat Penelitian, Diharapkan memberi materi tentang perdarahan intrakranial karena kekurangan vitamin $\mathrm{K}$ pada saat penyuluhan atau acara seperti posyandu. Hal ini sangat berguna karna dapat menambah wawasan masyarakat tentang perdarahan intrakranial karena kekurangan vitamin $\mathrm{K}$ dan bagaimana cara pencegahannya.

Bagi Peneliti Selanjutnya, diharapkan dapat menjadi acuan untuk melakukan penelitian tentang perdarahan intrakranial karena kekurangan vitamin $\mathrm{K}$ dengan menggali informasi terkait faktor penyebab perdarahan intrakranial karena kekurangan vitamin $\mathrm{K}$ sampai dengan tindakan pencegahannya.

Bagi Masyarakat, Masyarakat diharapkan dapat memperhatikan tentang pengetahuan perdarahan intrakranial karena kekurangan vitamin $\mathrm{K}$, sehingga angka kejadian perdarahan intrakranial karena kekurangan vitamin $\mathrm{K}$ dan kematian bayi dapat berkurang.

Bagi Institusi Pendidikan, Bagi institusi, agar dapat memberikan pengetahuan bagi mahasiswa-mahasiswi mengenai faktor-faktor yang bisa menyebabkan terjadinya perdarahan intrakranial karena kekurangan vitamin K. Dan diharapkan agar dapat meningkatkan mutu dan pelayanan pendidikan yang berkualitas dan professional, agar terciptanya tenaga kesehatan yang professional, terampil, cekatan dan handal dalam memberikan pelayanan.

\section{UCAPAN TERIMA KASIH}

Ucapan terima kasih kami sampaikan kepada Pemerintah Kota Prabumulih, Dinas Kesehatan, Puskesmas Prabumulih yang telah banyak membantu dalam penelitian ini

\section{DAFTAR PUSTAKA}

1. Rizka, Gambaran Perdarahan Intrakranial pada Perdarahan akibat Defisiensi Vitamin K (PDVK) di RSUP Dr. M. Djamil Jurnal Kesehatan Andalas. 2017; 6(2).

2. Volpe, Joseph J (2017-10-06). Neurology Volpe of the newborn (edisi keenam). ISBN 978-0-32342876-7 . Diakses tanggal 19 Oktober 2020 .

3. Supriyatno,B, Kegawatdaruratan Pada Bayi dan Anak. Jakarta: FKUI; 2012.

4. Edward, Pentingnya Profilaksis Vitamin K1 Pada Bayi Baru Lahir Damianus Journal of Medicine. 2011; Vol.10 No.1 Februari 2011: hlm. 51-55.

5. Kementerian Kesehatan Republik Indonesia. Pedoman teknis pemberian injeksi vitamin K1 profilaksis pada bayi baru lahir. Jakarta: Departemen Kesehatan Republik Indonesia; 2012

6. Danielsson N, Hoa DP, Thang NV, Vos T, Loughnan PM. Intracranial haemorrhage due to late onset vitamin $\mathrm{K}$ deficiency bleeding in Hanoi Province, Vietnam. Arch Dis Child Fetal Neonatal 2004;89:546-50.

7. Ijland MM, Pereira RR, Cornelissen E a M. Incidence of late vitamin $\mathrm{K}$ deficiency bleeding in newborns in the Netherlands in 2005: evaluation of the current guideline. Eur J Pediatr [Internet]. 2008 Feb [cited 2014 Mar 19];167(2):165-9. Available from: http://www.pubmedcentral.nih.gov/articlerender. fcgi?artid=2151775\&tool=pmcentre $\& \&$ rendertyp $\mathrm{e}=\mathrm{abstract}$

8. Eventov-Friedman S, Vinograd O, Ben-Haim M, Penso S, Bar-Oz B, Zisk-Rony RY. Parents' knowledge and perceptions regarding vitamin $\mathrm{K}$ prophylaxis in newborns. J Pediatr Hematol Oncol [Internet]. 2013 Jul;35(5):409-13. Available from: http://www.ncbi.nlm.nih.gov/pubmed/23242324

9. Miyao M, Abiru H, Ozeki M, Kotani H, Tsuruyama T, Kobayashi N, et al. Subdural hemorrhage: A unique case involving secondary vitamin $\mathrm{K}$ deficiency bleeding due to biliary atresia. Forensic Sci Int [Internet]. Elsevier Ireland Ltd; 2012 Sep 10 [cited 2014 Mar 24];221(1-3):e25-9. Available from:http ://www.ncbi.nlm.nih.gov/pubmed/22607980

10. Notoadmodjo, S. . Kesehatan Usia Lanjut dengan Pendekatan Asuhan Keperawatan. Kesehatan 
Masyarakat. Jakarta: Rineka Cipt Tamher, Jakarta. Salemba Medika; 2012

11. Wahyu, Gambaran Tingkat Pengetahuan Ibu Tentang ASI Eksklusif pada Ibu Menyusui Bayi Usia 0 - 6 Bulan di Rumah Bersalin "Nur Hikmah". Skripsi.Universitas Sumatra Utara; 2014. 